Clinica Chimica Acta, 45 (1973) 299-306

C) Elsevier Scientific Publishing Company, Amsterdam - Printed in The Netherlands

CCA 5669

\title{
EXCRETION OF TETRAHYDROALDOSTERONE IN NORMAL PREGNANCY
}

CARLOS POSADAS*, A. JAMES Blair, Jr. and DAISY S. McCANN**

Departments of Medicine, Wayne County General Hospital, Eloise, Mich. $4^{81}{ }^{2}{ }^{2}$ and the University of Michigan, Detroit, Mich. (U.S.A.)

(Received November 28, I972)

SUMMARY

While numerous studies of aldosterone I8-glucuronide excretion in pregnancy have been published few data have been available about the other major catabolite of aldosterone, the $3 \alpha, 5 \beta$-tetrahydro derivative.

Tetrahydroaldosterone, measured by gas chromatographic techniques, is higher in the luteal phase than in the follicular phase of nonpregnant young women. A wide range in tetrahydroaldosterone excretion was noted in pregnant subjects on unrestricted salt intake at the same stage of gestation. While some values remained at those levels encountered during the menstrual cycle, even in the last trimester of pregnancy, the average excretion generally rose with added weeks of gestation. The increases in tetrahydroaldosterone excretion are smaller than those reported by other workers for the I8-glucuronide aldosterone metabolite, supporting the suggestion made by K. M. Jones, R. Lloyd-Jones, A. Riondel, J. F. Tait, S. A. S. Tait, R. D. Bulbrook and F. C. Greenwood (Acta Endocrinol., 30 (I959) 32I), as well as by J. F. Tait and B. Little ( $J$. Clin. Invest., 47 (Ig68) 2423), that aldosterone metabolism is altered in pregnancy.

\section{INTRODUCTION}

For a number of years, it has been known that aldosterone production is increased in pregnancy. Flevated secretion ${ }^{1,2}$ and excretion ${ }^{3}$ of the hormone have been reported. More recently, Weir and associates ${ }^{4}$ reported an increased plasma aldosterone concentration in normal pregnant women. From the reports of Laidlaw et al. ${ }^{5}$, who detected very low urinary excretion of aldosterone by two bilaterally adrenalectomized women during pregnancy, and of Baulieu et al. ${ }^{6}$, who found no aldosterone in the urine of a pregnant woman with Addison's disease, it has been assumed that in

* Present address: Department of Endocrinology, Instituto Nacional de Cardiologia, Mexico City (Mexico).

** Reprint requests should be addressed to Daisy S. McCann, Department of Medicine, Waync County General Hospital, Eloise, Mich. $4^{81} 3^{2}$ (U.S.A.). 
humans the origin of aldosterone is adrenal rather than placental. However, Pasqualini et al. ${ }^{7}$ and Dufau and Villee ${ }^{8}$ have reported that the adrenal cortex of human fetuses is able to convert progesterone to aldosterone in vitro. Bayard et al. ${ }^{9}$ infused radioactively labelled aldosterone intravenously into mothers before delivery, subsequently detected the labelled steroid in fetal blood, and thus demonstrated the ability of aldosterone to cross the placenta. Assuming that equilibration had been reached during the infusion, they also concluded that, since the specific activity of aldosterone was less in fetal than in maternal blood, fetal secretion of aldosterone before birth was demonstrated.

The aldosterone secreted by the adrenal gland is found in urine in three forms: free aldosterone, aldosterone released from the acid labile conjugate, presumed to be aldosterone I8-glucuronide, and tetrahydroaldosterone glucuronide. The first two compounds have been measured in pregnancy ${ }^{1,3}$, on both unrestricted and controlled sodium intakes. However, to our knowledge, no report has been published on the urinary excretion of the tetrahydro metabolite by normal pregnant women. Hence, the present study was undertaken to determine the urinary levels of $3 \alpha, 5 \beta$-tetrahydroaldosterone (THA) in women with uncomplicated pregnancies on normal unrestricted sodium intakes. A modification of the techniques of Nicolis et al. ${ }^{10,11}$ using gas-liquid chromatography (GLC) with electron capture detection was used to quantitate the THA.

\section{MATERIALS AND METHODS}

\section{Subjects}

Twenty-three normal pregnant women, ranging in age from 17 to 36 years were studied. The gestation time of the pregnancy was estimated from the first day of the last normal menstrual period. The subjects were divided into first, second and third trimester groups.

Ten normal nonpregnant female control subjects were in the age range 20-26. Five were in the follicular phase and five in the luteal phase of their menstrual cycles. Seven normal young men, between the ages of I9 and 3 I were also studied.

All of the subjects, pregnant and nonpregnant, were ambulatory, and their dietary intake of sodium was unrestricted since the object of the study was to follow variations in THA secretion as it actually occurs in representative American pregnancies.

Urine was kept cold during the collection period, and no preservative was added. Completeness of the collection was monitored by creatinine determinations.

\section{Reagents}

Benzene, ethyl acetate and acetone were nanograde and used without further purification. Other solvents were of reagent gradc and distilled twice through allglass fractionating columns.

$d-\left[\mathrm{I}, 2^{-3} \mathrm{H}\right]$ Aldosterone, specific activity $42 \mathrm{Ci} / \mathrm{mM}$ and $\left[\mathrm{I}, 2^{-3} \mathrm{H}\right] \mathrm{THA}$, specific activity $32 \mathrm{Ci} / \mathrm{mM}$, were obtained from New England Nuclear, and purified by thinlayer chromatography (TLC) before use. Standard THA $\gamma$-lactone was prepared by enzymatic reduction of $d$-aldosterone $\gamma$-lactone ${ }^{11}$. The method described by Tomkins ${ }^{12}$ was used to prepare the appropriate $5 \beta$-reductases. 
The etiolactones of THA and I8-hydroxytetrahydrocorticosterone used for reference, were kindly donated by Dr. Stanley Ulick. Nonradioactive $d$-aldosterone was purchased from Sigma. The heptafluorobutyric anhydride was obtained in $1.0 \mathrm{ml}$ pre-scored ampules (Pierce Chemical Company, Rockford, Ill. U.S.A.) and stored in a desiccator.

Plates for TLC (Brinkmann Instruments Incorporated, Westbury, N.Y., U.S.A.) were $5 \times 20 \mathrm{~cm}$ and precoated with $0.25 \mathrm{~mm}$ of Silica Gel F-254. To remove impurities they were washed with methanol, then stored in a cabinet desiccator.

Tritium was counted in a Packard Tri-Carb liquid scintillation spectrometer Model 33I0. The scintillation fluid was prepared with $4.0 \mathrm{~g}$ of PPO, IOo $\mathrm{mg}$ of BBOT (Packard Instruments Company) in I 1 of toluene.

Following chromatography, the plates were scanned for radioactivity on a Packard Radiochromatogram Scanner Model 720 .

The GLC estimation was carried out on an F \& M (Hewlett-Packard) Model 402 instrument equipped with a Nickel-63 electron capture detector. A 3-foot, $0.4 \mathrm{~mm}$ internal diameter, $U$ shaped, glass column, packed with $\mathrm{I} \% \mathrm{XE} 60$ on Gas Chrom $Q$, 80-I0o mesh (Applied Science Lab) was conditioned for 3 days before use. Argon with $5 \%$ methane, which was passed through a molecular sieve before entering the column was used as the carrier gas.

The conditions at the time of analysis were: column $230^{\circ}$, detector $290^{\circ}$; carrier gas flow $85 \mathrm{ml} / \mathrm{min}$. Samples were injected on the column with a Io- $\mu$ l Hamilton syringe.

\section{Procedure for the isolation of THA from urine}

The method involves the following steps: hydrolysis, extraction, periodic acid oxidation of THA, TLC of the lactone of THA, formation of the heptafluorobutyrate derivative, TLC of this compound, followed by gas chromatography. Initially, another TLC was performed before the oxidation of THA. However, when the results of the three TLC were compared with those obtained by two TLC procedures, no significant difference was found.

Approximately $80000 \mathrm{cpm}$ of purified $\left[\mathrm{I}, 2^{-{ }^{3}} \mathrm{H}\right] \mathrm{THA}$ are added to $\mathrm{I} \%$ of a 24 -h urine collection, which is incubated with Iooo $\mathrm{U} / \mathrm{ml}$ of a mixture of $\alpha$-glucuronidase and sulfatase (glusulase), for $24 \mathrm{~h}$, at $45^{\circ}$ and $\mathrm{pH} 5$. The samples may also be incubated at $37^{\circ}$ for a period of $48-63 \mathrm{~h}$ without any change in results. After hydrolysis, the samples are filtered (this maneuver was found to be critical in preventing emulsion formation), and three extractions with I volume of ice-cold ethyl acetate are carried out. The extracts are pooled and washed three times with $4 \mathrm{ml}$ of $0.2 \mathrm{~N} \mathrm{NaOH}$, and then with water, followed by evaporation to dryness in a flash evaporator at $35^{-40^{\circ}}$.

The residue is transferred to a conical stoppered tube with the aid of $6-8 \mathrm{ml}$ of nanograde ethyl acetate. After evaporation under nitrogen, the samples are oxidized with periodic acid as described by Nicolis ${ }^{11}$, and extracted three times with $2 \mathrm{ml}$ of methylene chloride. The combined extracts are washed three times with $1.5 \mathrm{ml}$ of I.o $N \mathrm{NaOH}$, three times with $2.0 \mathrm{ml}$ of water, and again evaporated to dryness under nitrogen. To separate the products from the reaction mixture, TLC is performed in the system ethyl acetate-benzene $(6: 4, v / v)$. THA $\gamma$-lactone, $R_{F} 0.30$, separates from THA, which remains at the origin. The $\gamma$-lactone derivative is located by scanning and eluted with acetone. 
After evaporation of the solvent the formation of the heptafluorobutyrate derivative is carried out by incubating each sample with $2.0 \mathrm{ml}$ of $\mathrm{r} \%$ heptafluorobutyric anhydride and $0.5 \%$ tetrahydrofurane in benzene at $60^{\circ}$ for 43 min. Samples are thoroughly dried under nitrogen, and then chromatographed on thin layer plates, which are developed in the system benzene-ethyl aretate $(95: 5, v / v)$. The zone containing the final derivative, $R_{F} 0.44$, is eluted with $2.0 \mathrm{ml}$ of benzene-ethyl acetate $(\mathrm{I}: \mathrm{r}, \mathrm{V} / \mathrm{v})$. The zone to be eluted is defined as comprising $8 \mathrm{~mm}$ on either side of the radioactive peak. The solvent is again evaporated under nitrogen.

Before GLC, samples are dissolved in $0.025-0.5 \mathrm{ml}$ of benzene and $2-5 \mu \mathrm{I}$ are injected into the gas chromatograph, and a suitable aliquot is added to scintillation fluid and counted to assess the recovery obtained throughout the purification steps.

Standard curves are routinely obtained before and after injection of the samples. It has been found convenient to monitor the sensitivity of the instrument occasionally, by injecting a known amount of pure THA $\gamma$-lactone heptaflurobutyrate standard among samples. Should the sensitivity change, another standard curve is obtained before proceeding with the analysis of samples.

\section{RESULTS}

Precision was evaluated on the basis of the coefficient of variation of duplicate determinations of samples derived from 12 subjects. It was of the order of $4.0 \%$ with a standard deviation of $3.5 \%$. In a separate series of studies the reproducibility of the method using 2 as compared to 3 thin layer chromatograms was determined. Again for a series of urines from $\mathrm{I} 2$ subjects, this was found to be $6 . \mathrm{I} \pm 6.7 \%$.

Recovery of $\left[{ }^{3} \mathrm{H}\right]$ THA added as a tracer was found to be $27.4+8.8 \%$ (standard deviation). It is, therefore, necessary to correct final values routinely for the recovery of added internal standard. In addition, of course, the radinactive tracers are used for locating the appropriate compounds after TLC.

The use of the heptafluorobutyrate derivative of THA $\gamma$-lactone, allows the measurement of extremely small amounts of the steroid by GLC with electron capture detection. In our hands, under the conditions described, the smallest amount which could be quantitated accurately without using the maximum sensitivity of the G.C. was o.Io ng. In practice, however, it was not necessary to work with such small amounts; generally, the standard curve was obtained by injecting 0.5, I.o, I.5 and $2.0 \mathrm{ng}$ of pure standard. Because the sensitivity is high, only small amounts of urine need to be worked up. This facilitates handling and yields better recoveries in the periodic acid oxidation step and the formation of the heptafluorobutyrate derivative than the use of $50 \mathrm{ml}$ or more of urine.

The heptafluorobutyrate-THA lactone peaks obtained from urine extracts have the same retention time as those of pure heptafluorobutyrate-THA lactone standard. Water blanks taken through the entire procedure gave no peak in the derivative region. The likeliest interference, 18 -hydroxytetrahydrocorticosterone, was shown to have a different retention time (II.5 min) in the column used. The results for control subjects are in good agreement with values previously reported by other investigators ${ }^{10}$. Finally Nicolis et al. ${ }^{10}$ used infra-red spectrophotometry and a rather similar system involving TLC and acetylation with monochlorodifluoracetic anhydride showed identity between the product obtained from urine and authentic standards. 


\section{THA urinary excretion in normal men and women}

THA excretion by seven normal male subjects on an uncontrolled diet ranged from $\mathrm{I} 2$ to $36 \mu \mathrm{g}$ per day, with a mean of $2 \mathrm{I} \mu \mathrm{g}$ (Fig. I).

The 24-h urinary excretion of THA was measured in ten nonpregnant women on a free salt intake. Five were in the follicular phase and five in the luteal phase of their menstrual cycles. The aim was to determine whether there were changes in the THA excretion rate during this period. It is evident (Fig. I) that there was a significant rise in the THA excretion during the luteal as compared to the follicular plase, the mean THA excretion of $66 \mu \mathrm{g}$ per day during the former period being almost double the $36 \mu \mathrm{g}$ per day observed during the follicular phase.

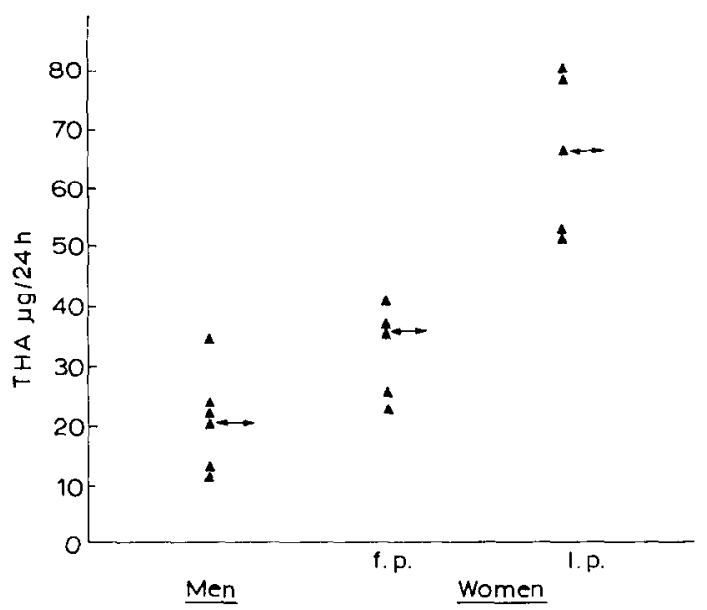

Fig. I. THA excretion in normal men and women. f.p. and 1.p. stand for follicular and luteal phases of the menstrual cycle, respectively.

\section{THA excretion in normal pregnant subjects}

A wide range in THA excretion was noted in different subjects at the same stage of gestation. Fig. 2 shows the THA excretion measured in I I subjects from weeks 9 to I3 of gestation. While three subjects in this group showed a significant elevation in THA excretion, most of the subjects remained within the range of values found in the series of nonpregnant women. The mean value of $90 \mu \mathrm{g} /$ day for that group is somewhat higher than the THA excretion of the nonpregnant women in the luteal phase of the menstrual cycle. The values found for 16 determinations in eight subjects from weeks I 6 to 27 are shown in the same figure. In this group Io values are either slightly or markedly elevated above the normal range. The mean value of $105 \mu \mathrm{g} /$ day found in this group is again higher than that of nonpregnant women or of the first trimester group. The women pregnant from weeks 28 to 40 showed the highest THA excretion with a mean for $2 \mathrm{I}$ determinations in $\mathrm{I} 3$ subjects of $\mathrm{I} 66 \mu \mathrm{g} /$ day. However, four values were still within the range of the nonpregnant women in the follicular phase.

Serial determinations of THA excretion in three pregnant subjects are shown in Fig. 3. In all three subjects, there was considerable fluctuation in THA excretion measured during the progression of pregnancy. In subjects G.C. and D.F., a fall in THA excretion was noted near term, but subject D.C. demonstrated a rise in THA excretion at 39 weeks. In all three the values shortly after delivery were lower than those during pregnancy. 


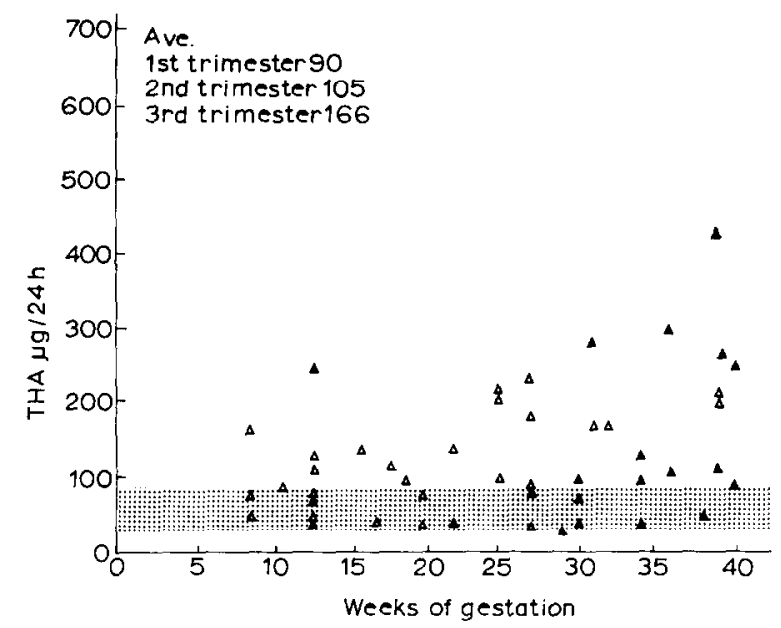

Fig. 2. THA excretion in uncomplicated pregnancy. The first group of closed triangles corresponds to subjects in the first trimester, the open triangles to those in the second trimester and the last group of closed triangles to those in the last trimester of pregnancy.

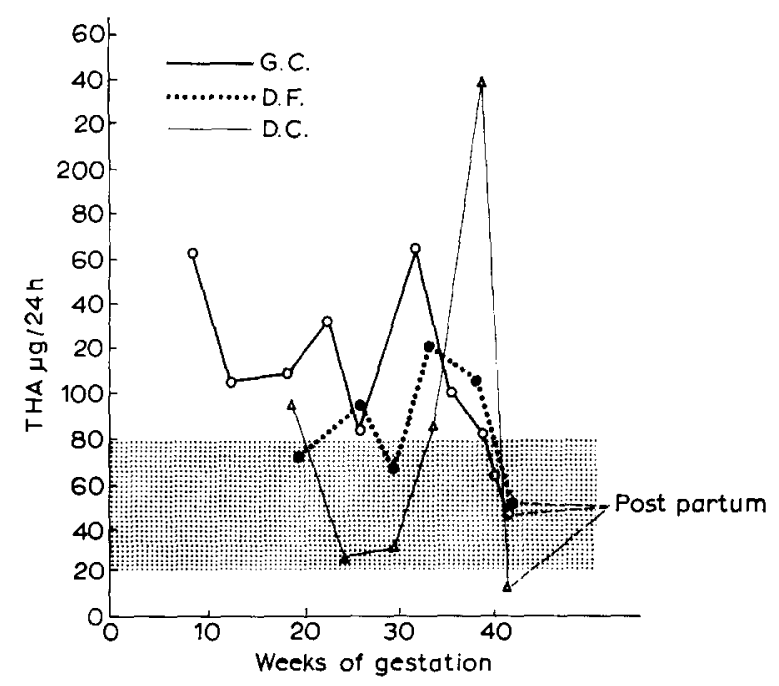

Fig. 3. Serial THA excretion during uncomplicated pregnancy.

DISCUSSION

The increase in THA excretion reported here during the luteal as compared to the follicular phase of the menstrual cycle parallels reports by other workers who measured aldosterone $\mathrm{I} 8$-glucuronide excretion. Thus Haines et al. ${ }^{13}$ found a mean value of $5.8 \mu \mathrm{g}$ per day of aldosterone I8-glucuronide (range $2.8-7.5$ ) during the follicular phase and $9.7 \mu \mathrm{g}$ (range 2.0-22) during the luteal phase. The increase in THA excretion also correlates with the rise of aldosterone secretion rate in the luteal phase observed by Gray et al. ${ }^{\mathbf{1 4}}$ who reported values for aldosterone secretion rates of $\mathrm{I} 39$ and $235 \mu \mathrm{g}$ per day during the follicular and luteal phase, respectively.

The urinary excretion, and secretion of aldosterone have been reported to be 
increased in normal pregnancy ${ }^{\mathbf{1 - 3}}$. More recently, plasma aldosterone concentration was found to be elevated in normal, gravid subjects on unrestricted diets ${ }^{4}$. It is also known that aldosterone secretion in normal pregnant women, as in nonpregnant subjects, is inversely related to sodium intake, the highest values being observed in subjects receiving a sodium diet of less than ro mequiv/day ${ }^{2}$. Despite the large amount of data on the increased secretion and excretion of aldosterone by normal pregnant women, the mechanisms responsible for this elevation are still not well understood. Several factors that may play a role in the enhancement of aldosterone production during pregnancy have been suggested. First, it is well known that during pregnancy the sodium load which is filtered is increased. Also there is sodium retention ${ }^{15}$ required to meet the needs of the developing products of conception. However, neither of these factors have provided a really satisfactory explanation for the great increase in aldosterone secretion ${ }^{2}$.

Progesterone has natriuretic activity, due to competitive inhibition of aldosterone action on the distal renal tubule ${ }^{16}$. Biglieri ${ }^{17}$ reported a case of primary aldosteronism in a woman, who showed a marked improvement of the manifestations of the disease during pregnancy; this amelioration was attributed to the antialdosterone action of the increased production of progesterone in pregnancy. The administration of progesterone has been shown to increase aldosterone production in normal persons (refs. I8, I9) and in subjects with normal pregnancy as well as in patients with a pregnancy terminated by intra-uterine fetal death ${ }^{20}$. Jones et al. ${ }^{1}$ demonstrated a direct correlation between aldosterone secretion and urinary pregnanediol excretion in pregnancy. It has been suggested that the increase in aldosterone constitutes a compensatory mechanism against the antagonism of high levels of progesterone ${ }^{21}$. The picture may in fact be even more complicated since Ehrlich et al. ${ }^{21}$ have published data suggesting that progesterone secretion per se may be altered by variations in salt intake. In any event, there appears to be a relationship between the high concentration of progesterone and the increased production of aldosterone in human pregnancy. However, while the maintenance of normal pregnancy requires progressive increases in progesterone production, a positive and quantitative relationship between the level of aldosterone production and the duration of gestation would not seem to be necessary.

The role of the renin-angiotensin system in mediating a high aldosterone secretion rate in pregnancy as reviewed recently ${ }^{22}$ is uncertain. Plasma renin concentration is variably increased, remaining within the normal nonpregnant range in some women. An increased level of renin substrate has consistently been found in human pregnancy. No significant relationship has been demonstrated in pregnancy between plasma aldosterone and either plasma renin, or plasma renin substrate. However, a significant correlation between plasma aldosterone and the product of plasma renin and renin substrate concentrations has been demonstrated.

Serial simultaneous measurements of both metabolites in the urine of a pregnant woman with primary aldosteronism ${ }^{17}$ showed a gradual increase in the ratio of aldosterone: THA from 0.45 before pregnancy to $\mathrm{r}$. 3 in the eighth month of gestation. This change in metabolism does not seem to be related to factors such as binding of aldosterone to plasma proteins other than albumin, or changes in the metabolic clearance rate of aldosterone, which appear to be unaltered in pregnancy ${ }^{\mathbf{2 3 , 2 4}}$.

The increase in urinary excretion of THA observed in our subjects are smaller 
than the increments reported in the literature for the acid-labile conjugate of aldosterone. Therefore, although we did not measure the excretion rate of this conjugate of aldosterone, our data support the finding of Jones et al. ${ }^{1}$ and Tait and Little ${ }^{25}$ who reported an altered metabolism of aldosterone in pregnancy. Both groups demonstrated an increascd conversion of aldosterone to the acid-labile conjugate with a relatively decreased formation of THA in pregnant subjects.

In summary, then, our data suggests that there is a considerable increase in THA excretion in most, but not all, subjects during pregnancy. While the increase is marked it does not appear to be as great as the increase reported for the excretion of the other major aldosterone metabolite, aldosterone 18 -glucuronide.

\section{ACKNOWLEDGEMENTS}

These studies were supported by grants from the Medical Staff Research and Education Fund, Wayne County General Hospital and the Upjohn Company, Kalamazoo, Mich., U.S.A.

We are grateful to Mr. Aaron Abramovitz and to Mr. Nick C. E. Tarcia for technical assistance.

\section{REFERENCES}

I K. M. Jones, R. Lloyd-Jones, A. Riondel, J. F. Tait, S. A. S. Tait, R, D. Bulbrook and F. C. Greenwood, Acta Endoctinol., 30 (1959) $32 \mathrm{I}$.

2 M. Watanabe, C. I. Meeker, M. J. Gray, E. A. H. Sims and S. Solomon, J. Clin. Invest., 42 (I963) I619.

3 D. Kumar, L. A. W. Feltham and A. G. Gornall, Lancet, i (r9.59) 54 I.

4 R. J. Weir, D. B. Paintin, J. I. S. Robertson, M. Tree, R. Fraser and J. Young, Proc. Roy. Soc. Med., 63 (I970) I IOI.

5 J. C. Laidlaw, M. Cohen and A. G. Gornall, J. Clin. Endocrinol., I8 (1958) 222.

6 F. E. Baulieu, M. DeVigan, H. Rricatrf. ano M. F. Javi.k, J Clin. Findoryinol, i 7 (1957) $\mathrm{T} 47^{8}$.

7 J. R. Pasqualini, N. Wigvist and E. Diczfalusy, Biochim. Biophys. Acta, i 2 I (ig66) 430.

8 M. L. Dufau and D. B. Villee, Biochim. Biophys. Acta, 176 (1969) 637.

9 F. Bayard, I. B. Ances, A. J. Tapper, V. V. Weldon, A. Kowarski and C. J. Migeon, J. Clin. Invest., 49 (1970) 1389 .

io G. L. Nicolis, H. H. Wotiz and J. L. Gabrilove, J. Clin. Endocrinol., 28 (I968) 547.

i G. I. Nicolis and J. L. Gabrilove, J. Clin. Endocrinol, 29 (r969) I5ig.

i 2 G. M. Tomkins, S. P. Colowick and N. O. Kaplan (Eds.), Methods in Enzymology, Vol. V, Academic Press, New York, 1962, p. 499.

i 3 J. E. Haines, D. S. Newport and T. T. Hutchens, in R. I. Dorfman (Ed.), Methods in Hormone Research, Vol. I, Academic Press, New York, 1968, p. $34^{8}$.

I4 M. J. Gray, K. S. Strausfeld, M. Watanabe, F. A. H. Sims and S. Solomon, J. Clin. Endocrinol., 28 (I968) I 269.

i 5 E. H. Venning, I. Dyrenfurth, L. Lowenstein and J. Beck, J. Clin. Endocrinol., i 9 (1959) 403 .

I6 R. L. LaNDaU and K. I.Ugibihl, J. Clin. Endocrinol., I 8 (I958) I 237 .

i7 E. G. Biglieri and P. E. Slaton, Jr., J. Clin. Endocrinol., 27 (I967) I628.

18 D. S. Layne, C. J. Meyer, P. S. Vaishwanar and G. Pincus, J. Clin. Endocrinol, 22 (1962) 107 .

i9 J. C. Laidlaw, J. L. Ruse and A. G. Gornall, J. Clin. Endocrinol, 22 (Ig6z) i6i.

20 M. Watanabe, C. I. Meeker, M. J. Gray, E. A. H. Sims and S. Solomon, J. Clin. Endocrinol, 25 (I965) I 665.

21 E. N. Ehrlich, M. Laves, K. Lugidill and R. L. Landau, J. Lab. Clin. Mod., 59 (I962) 588

22 J. I. S. Robertson, R. J. Weir, G. O. Dusterdieck, R. Fraser and M. Tree, Scot. Med. J., I6 (I97I) I 83 .

23 C. J. Meyer, D. S. I.ayne, J. F. Tait and G. Pincus, J. Clin. Invest, 40 (196i) i 663.

24 J. F. Tajt, B. LiThle, S. A. S. Tait and C. Floov, J. Clin. Invest. 4 i (ig6r) 2093.

25 J. F. Tatt and B. Little, J. Clin. Invest, 47 (I968) 2423 